\title{
Institutional Barriers to Doing Public Sociology: Experiences of Feminists in the Academy
}

\author{
Joey Sprague • Heather Laube
}

Published online: 2 September 2009

(C) Springer Science + Business Media, LLC 2009

\begin{abstract}
In recent years, the discipline of sociology has seen an increased discussion of public sociology, but the discussion has focused on whether or not it is a good idea for sociologists to become more engaged with their various publics. A different question motivates this research: What are the institutional arrangements that make doing public sociology difficult, and thus less likely? Following Dorothy Smith, we start from the perspective of frontline actors and ask them about their experiences. We combine data from two sources: individual interviews with a sample of 50 academic feminists, a group that has theoretical motivation to be interested in public sociology and group interviews with 15 feminists engaged in some form of public sociology. These informants tell us about two related institutional barriers to doing public sociology: the culture of professional sociology and the standards we use for evaluating scholarship. The impact of these disciplinary barriers probably varies by institution type and career stage but there is reason to suspect they generate costs not just for individuals but for the discipline. Taking steps to break down these barriers would ameliorate concerns some have raised about public sociology.
\end{abstract}

Keywords Public sociology $\cdot$ Feminist methodology $\cdot$ Evaluation practices

\footnotetext{
J. Sprague $(\bowtie)$

University of Kansas, 706 Fraser Hall, Lawrence, KS 66045, USA

e-mail: jsprague@ku.edu

H. Laube

University of Michigan-Flint, 522 French Hall, Flint, MI 48502, USA

e-mail: hlaube@umflint.edu
} 
In recent years, thanks in no small part to the leadership of Michael Burawoy, the discipline of sociology has seen increased discussion about engaged forms of sociological practice under the rubric of public sociology (Blau and Smith 2006; Brady 2004; Burawoy 2006, 2005a, b, 2004; Burawoy et al. 2004; Nielsen 2004; Tittle 2004). Most of the discussion has focused on whether or not public sociology is a good idea. In this paper we pose a different question: Even if sociologists might reach disciplinary consensus that sociology's engagement in public discourse is a good thing, how likely is high quality engagement given the organization of sociology as profession? That is, do our standard institutional arrangements make doing public sociology difficult, and thus less likely?

First we review the main themes in the contemporary discussion about public sociology. Then we begin to examine the degree to which public sociology is possible in the current social organization of the discipline by learning from the experiences of feminist sociologists working in the academy. We conclude by suggesting that revising the social organization of the discipline would go a long way in ameliorating some sociologists' concerns about public sociology.

\section{The History of Useful Sociology}

While sociology began as an enterprise engaged with the community and that engagement was prominent until the mid-twentieth century (McAdam 2007), an indicator of the degree to which mainstream sociology had retreated into the academy by the beginning of the 21 st century is that Burawoy had to begin his effort to legitimize sociological work that reaches outside of academic discourse by naming it.

Burawoy (2004) categorizes the work sociologists do into four types: professional, critical, policy, and public sociologies. Professional and critical sociology, Burawoy says, are directed toward an audience of peers and subject to their review. He describes professional sociology as developing the content of sociology, theory and empirical findings. Critical sociology challenges the assumptions underlying the work of professional sociology and "seeks to remind professional sociologists of their place in the world" (Burawoy 2004:105). Both policy and public sociology, in Burawoy's scheme, are directed at audiences outside of the academy. Policy sociology refers to work done at the request of and directed by the goals of a specific sponsor. Public sociology is a more amorphous category of efforts to bring the tools or findings of sociological research into settings outside of the academy, including working with community groups and communicating with members of the press. Burawoy argues that these four ways of doing sociology are compatible, even interdependent. Professional sociology provides the "ammunition, the expertise, the knowledge, the insight, and the legitimacy" on which public and policy sociology depend, while critical sociology is "the guardian of the discipline and the conscience of professional sociology" (2004:105).

In developing this typology, Burawoy elaborates on the distinction U.S. sociology has made since its early days between "basic" and "applied" sociology. As Burawoy conceptualizes them, policy and public sociologies fit under the general umbrella of the notion of applied sociology, which Wimberly defines most broadly as "what 
sociologists do for non-sociologists and sometimes for themselves" (1998:5). Note that both Burawoy's typology and, to some extent, Wimberly's definition assume that the discipline's knowledge base has little to gain from the work of those who attempt to apply its ideas in real world contexts. The core values of the discipline tend to devalue applied work.

Perhaps the most objective evidence of the degree to which U.S. sociology has devalued applied work is the regularity with which the discipline has shed subspecialties over the course of its history. The discipline has from its beginnings experienced a split. On one side were academics who were more focused on developing sociological knowledge and who believed this required detachment from engagement in ongoing social struggle. On the other side were social reformers like those around Jane Addams at Hull House who worked to apply the tools of sociology to address social problems (Best 2001; Deegan 1988). As Best tells the history, "eventually the scholars won: the reformers mostly abandoned sociology" and were instrumental in establishing social welfare (2001:108-09).

This pattern-sociology developing something which had real world usefulness and then the practitioners splitting off-happened over and over again in the twentieth century, Best (2001) says. Polling went to political science and marketing, organizational studies went to public administration and management, and demography and criminal justice became separate fields. "It seems as though every time sociologists develop something that looks like it could turn a buck, we get rid of it" (Best 2001:109). By the 1950s, what Hand and Judkins (1999) describe as the smoldering feud between reformers and detached scholars seemed to be resolved in favor of those who argued that engagement in attempts to fix society undermined the scientific credibility of the discipline.

Then, at the end of the 1970 s the tide seemed to be turning toward valuing engaged sociology, including proponents forming professional organizations and beginning journals. One journal founded at the time, Sociological Practice Review, is now an official journal of the American Sociological Association (ASA) (Hand and Judkins 1999). By 1989, roughly $38 \%$ of undergraduate programs, $11 \%$ of MA programs, and $4 \%$ of $\mathrm{PhD}$ programs reported some kind of training in applied or practice sociology (Hand and Judkins 1999). The decade between 1986 and 1996 saw a marked increase in the number of departments with programs focusing on applications of sociological knowledge, defined broadly to include criminology, demography, industrial sociology, marriage and family, medical sociology, rural sociology, sociological practice/social policy, sociology of aging/gerontology, urban sociology, and sociology of mental health (Hand and Judkins 1999).

Even if training in more applied fields has increased (and some of the areas in Hand and Judkins study are arguably not all that applied), there are also signs that the devaluing of comparatively applied work has continued. For example in 1998, even after a couple decades of growth, Wimberly felt obligated to say that "to be an applied sociologist is not a disgrace" and assert that it takes more skill to apply sociology than to simply create it (1998:11).

While Burawoy says that a particular sociologist might engage in more than one type of sociology, his elaboration appears to incorporate something about employment relationships. Policy sociology seems more likely to be conducted by those employed by others, while public sociology seems to be work done by those in 
the academy. People's concerns about the desirability of public sociology come across as apprehension about what it would mean for the status of academic sociology.

\section{The Current Debate}

One major theme in the current dialogue about public sociology echoes the longstanding debate between basic and applied sociologists over whether engagement conflicts with the goals of science and thus undermines the credibility of sociological scholarship. Some sociologists are concerned that public sociologists might let their political interests override their commitments to scientific standards (e.g., Braithwaite 2005; Inglis 2005; Sassen 2005; Stacey 2004; Tittle 2004). They question whether a sociology in which a normative stance is central can be a legitimate, scientific sociology. For example, Nielsen (2004) rejects the assumption that sociologists share a common set of values. Professional sociology, he argues, is grounded in moral detachment, while public sociology explicitly acknowledges the importance of values in research and he wonders how the two can comfortably coexist.

A second concern is that an engaged sociology will lead to distortions and oversimplifications of sociological analyses. Researchers may feel pressed to oversimplify their analyses and arguments to communicate with audiences of nonspecialists. Further, once their message enters public discourse scholars lose control of it, as stakeholders, decision-makers, journalists, and others reinterpret sociological knowledge from their own frames of reference and for their own purposes. The operating practices of global media make it likely that complex sociological analyses will be cut into "sound bites" that are repeated again and again without appropriate contextualization, leading to essentially false claims presented in the guise of scientific truth (Stacey 2004). Constant reinterpretation and word-of-mouth distribution risk that "the uses of sociological knowledge [will] have nothing to do with the sociological knowledge being used" (Beck 2005:336). Perhaps worse, Scott (2005) worries, without specialized terminology and methodological complexity, the contribution of sociology will disappear entirely and its messages will more closely resemble common sense than science, leaving audiences wondering why they need a sociologist to tell them things they already know.

A third line of criticism challenges the notion that public sociology is inherently moral or ethical. Lal (2008) notes that Burawoy's typology represents sociology as somehow independent of the particular political and economic context in which it exists. Yet universities are embedded in societies and often their context drives intellectual work. The emergence of area studies programs, Lal (2008) argues, illustrates the interconnectedness of the interests of the state and university. The programs, initiated during the Cold War by the Social Science Research Council, then a front organization for the CIA, reflected and fostered the interests of political and economic power structures, not purely intellectual pursuits. Lal offers an important ethical warning to those who advocate for public sociology: Which publics do sociologists want to advance and how can they avoid simply supporting the current hegemony and serve the broader social interests? 
On the other side of the discussion, advocates for public sociology maintain that becoming more engaged with audiences outside the academy is not only a moral imperative but that it is in the best interests of the discipline (e.g., Braithwaite 2005; Calhoun 2005; Etzioni 2005; Kalleberg 2005). For one thing, being engaged in more public discourse will increase the public's awareness of the importance of the work we do, thus bolstering their willingness to continue public support for it (Sprague 1998). If sociology is to have relevance in the social world, sociologists must demonstrate that they have something interesting and important to say.

More than continued support of taxpayers and legislatures is at stake, according to advocates. Burawoy's four types of sociology have gotten out of balance to the detriment of the discipline's ability to develop valid knowledge (Scott 2005). The autonomy allowed professional sociology facilitates sociologists' relatively unfettered pursuit of academic knowledge, but it has also led to increased isolation. Engagement with those outside of the discipline will increase the rigor of sociological scholarship (Sassen 2005; Smith 2005). Francesca Cancian (1992), for example, notes that the strongest test of sociological theories is their ability to direct social change in the real world laboratory of the community.

Smith (2005) elaborates on the consequences of non-engagement with the world for sociological knowledge. She argues that the conceptual frameworks of mainstream sociology transform everyday lived experience into a "virtual reality" that bears little resemblance to how things actually work and can mask the operations of power in shaping practices and choices (Smith 2005). Hale asserts that being embedded in an actual community provides an advantageous position to develop a deep, multifaceted, and complex understanding of the topic under study (2008:20). Those who are not bound by sociological disciplinary discourse will pose questions that can point sociologists to problematic assumptions and more productive inquiry. Because of the ways race, class, and gender structure the educational pipeline leading to a $\mathrm{PhD}$, marginalized communities are particularly fruitful grounds for developing a sensitivity to the biases in knowledge developed from more privileged social positions (Sprague 2005; c. f., Lipsitz 2008; Mendez 2008; Nabudere 2008). Finally, while professional sociologists are accountable to their peers, engaging with publics adds another layer of accountability, the need "to get it right" (Smith 2005). A commitment to a group motivates the scholar to conduct methodologically rigorous and socially useful research.

We agree that making sociology more public while creating high quality scholarship raises challenges and do not want to minimize their significance. In this paper, however, we address a question that has received little attention in the current conversation: How amenable is the discipline to the actual work of doing public sociology? Our question is in the tradition that Swidler and Arditi have labeled "the new sociology of knowledge," an approach that "expands the field of study from an examination of the contents of knowledge to the investigation of the forms and practices of knowing" (1994:306). We ask: How do the forms and practices of contemporary sociology limit the degree to which sociologists are likely to create knowledge that informs public discourse? 


\section{Methods}

Dorothy Smith (2005) argues that in order to understand how power works in our society, sociologists should begin with the accounts of everyday actors describing the circumstances of their work and how that work is organized by relationships outside of their daily context. Therefore, we draw on the experiences of sociologists in the trenches of the academy. Because feminist sociology is explicitly committed to understanding inequality in order to end it, we choose as informants feminists in academic sociology.

We pool two sets of data. One of us (Sprague) conducted three group interviews with self-identified public sociologists. Participants were recruited via the Sociologists for Women in Society's (SWS) electronic mailing list, with a request for faculty who identified themselves as people who were trying to do public sociology and who were planning on attending the organization's 2004 winter meeting. For this project, she defined public sociology as doing research that involves community members in some way-from setting the agenda, to working collaboratively to collect and interpret data, to talking about research findings to audiences other than academics.

From volunteers, she organized three somewhat homogeneous groups. One consisted of five junior scholars working at teaching intensive institutions, a second included six junior sociologists working at research intensive institutions, and the third comprised four senior scholars at either research intensive or comprehensive institutions. (There were not enough senior scholar volunteers attending the meeting to form separate groups for distinct institution types.) These interviews were semistructured and lasted an hour. Topics covered included the nature of informants' public sociology work, the kind of work they would like to do and why they are not doing it, the kind of support they get from their colleagues and institutions for this kind of work, and the things that would make the work easier to do.

The second source of data is individual interviews with 50 feminist academic sociologists (all women) conducted by the other one of us (Laube) in 2002. Initial recruits to this sample came from the most recent membership guide of SWS. At the end of each of those interviews, she asked the interviewee to suggest others who might be appropriate participants in the research and selected from those referrals to maximize sample balance in institution type and career stage (Singleton et al. 1993). Interviews were semi-structured, in-depth, and ranged in length from 45 minutes to two and a half hours. Respondents answered questions about the audiences they desired for their scholarship, how free they felt to pursue those audiences, and what it meant for them professionally when they pursued audiences outside of academia. They described how the types of institutions in which they work, evaluation practices, and tenure status shaped their choices about the degree to which they could practice engaged sociology.

Both sets of interviews were audio-taped and transcribed for analysis. Each author analyzed the data she collected using standard qualitative methods: repeated readings of the transcripts, reading along with the audio record, identifying recurring patterns, and searching for exceptions to those patterns (Miles and Huberman 1984; Strauss and Corbin 1990). Laube used NUD*IST Qualitative Data Analysis software to code emergent themes, reorganize data, and scrutinize her findings. Each author reviewed 
the transcripts of the other's data. There are two respondents who participated in both the focus groups and individual interviews resulting in a combined sample of 63 unique sociologists, including nine women of color. Table 1 describes the combined sample in terms of career stage and institution types, and indicates the types of public sociology in which informants reported engaging.

Ours were not probability samples so we cannot universalize our findings to the full population of academic sociologists, and, in the same vein, assessments of generalizability made by respondents cannot be viewed as conclusive. Nevertheless, our informants are trained sociologists with enhanced awareness of social structure and processes, and skills to analyze complex social situations (Weiss 1994). As women they occupy a distinct gender position from that of men in the academy and as feminists they are predisposed to a critical attitude. We feel we can offer a valuable, if partial, perspective on common practices in the discipline and in a variety of academic institutions, a point to which we will return later.

While our informants vary in career stage, institution type, and efforts to be more engaged, they are similar in the constraints they face. Again and again, two interrelated themes emerge in their talk: the culture of academic sociology and evaluation practices.

\section{The Culture of Academic Sociology}

Many of our informants talk about how the culture of professional sociology militates against their doing public sociology. Martha, a senior scholar at a highly ranked department, explained that she was the only person in her department who participated in her institution's efforts to do outreach. For her colleagues, engaging the public with an eye toward reducing inequality is simply not good sociology.

Sociology is not making change. Sociology is doing data analysis, quantitative data analysis, publishing in, you know, the top three journals. And that's what sociology is.

Table 1 Respondents reporting public sociology activity by rank and institution type

\begin{tabular}{llllllllll}
\hline Type & $\begin{array}{l}\text { \% of } \\
\text { sample }\end{array}$ & Rank & $n$ & $\begin{array}{l}\text { Report public } \\
\text { sociology }\end{array}$ & $\begin{array}{l}\text { Service } \\
\text { learning }\end{array}$ & $\begin{array}{l}\text { Student } \\
\text { groups }\end{array}$ & $\begin{array}{l}\text { Media } \\
\text { groups } \\
\text { gommunity }\end{array}$ & $\begin{array}{l}\text { Policy or } \\
\text { court }\end{array}$ \\
\hline $\begin{array}{c}\text { Top 25 } \\
\text { Depts. }\end{array}$ & 23 & Junior & 6 & 2 & & & 2 & & \\
Research & 37 & Senior & 9 & 6 & 1 & & 5 & 2 & 1 \\
& Junior & 10 & 9 & 2 & & 3 & 5 & 2 \\
Teaching & 40 & Senior & 13 & 12 & & 1 & 3 & 7 & 5 \\
Tunior & 11 & 10 & 4 & 1 & 5 & 3 & 3 \\
Total & Senior & 14 & 10 & 2 & 1 & 3 & 7 & 3 \\
of N & & 63 & 49 & 9 & 3 & 21 & 24 & 13 \\
\hline
\end{tabular}


Sociologists at major research universities do most of the graduate training in the discipline. If they, like Martha's colleagues, consistently emphasize this narrow definition of good sociological knowledge, it is not surprising that the public sociologists consistently report that their training in graduate school failed to give them the kinds of skills necessary for working with communities. Mary, a full professor at a research intensive university, learned this lesson well:

My feeling is ... that you do basic research and practitioners read the basic research and, ideally that sort of the root is their taking that basic research and making use of it for practice and policy — as opposed to my trying to craft it in that way. In fact my dissertation advisor, I remember when I, in fact, was going to write something - start with something about implications for practice and policy in my dissertation - she almost had, I mean she really had a fit. She said, "That is not sociology. Sociology is basic research, basic theoretical ideas with data - using data to examine those issues. Policy and practice just is not where we should be going." I'm not extremely sure, but obviously I was socialized heavily in that direction. And I did not have policy recommendations. It doesn't go in there.

Interviewees report that their work demands skills for which graduate school simply did not prepare them. Kate, a junior scholar at a teaching intensive institution, would like to use service learning to engage her students in working with community groups but feels ill equipped to do so.

But I feel so frustrated, I feel like I'm barely doing anything really scratching the surface in the community. And I have gone to different organizations like my community partners and my service learning courses and [asked] what kind of research can be done because I teach methods and right now I don't have them doing things. It's very introductory but I can see going that direction. But I don't feel equipped to do that, I don't feel really trained to do that and I haven't had much success in enlisting those kinds of projects.

Beyond failing to offer needed instruction, sociology may be training graduate students to be ineffective in communicating with the public. Many of our informants complain that the professional culture of sociology encourages a discourse that is very narrow in its potential reach-long-winded, technical, and filled with jargon. Virginia, a junior scholar at a research intensive school puts it this way:

My mother read my book manuscript and she said, "You used to be such a good writer!" [group laughs] "What happened?" They beat it out of me, Mom. [laughs] . . I I mean it's kind of like when we have-like every graduate student completely brutalizes the sociological concepts, you know, throws them in there, and we just get better at that and we actually know what they mean and so we use them more frequently to show that we know what they mean and then all of a sudden nobody can read what we write. 
Karen, an assistant professor at a research intensive institution, feels the same way:

I would love it if my scholarship on [a type of gender inequity] would reach a more general audience . . . more like, women in America-especially, nonacademic working women. But, to tell you the truth, I don't know how good I'd be at writing for a more general audience because my training has been-I, you know-I've been taught to write for academic audiences, which is very different.

Barbara, a full professor at a research intensive institution, has written a book on a form of violence against women and she and her publisher want to reach a broad audience.

I'm trying to write it so that nurses and cops and judges and prosecutors and that the attorneys will read it. It's the first time I've ever really tried to do that. I've made a lot of talks to non-academic groups, but I've never tried to write for non-academic audience and it's different. (laughs) But I really want to do it-besides which, I was kind of forced to by the publisher. But I still, I think it's a great idea. I learned-I was an English major and had to learn to write like a sociologist. Now I'm trying to unlearn that stuff. (laughs) It's very tough. So I would like to help society under - help ordinary people understand society. . . . It's not that I can't write. It's that I don't know how to-I, I'm not good-I don't know how to write for the public.

Even if sociologists practice more accessible writing strategies, the critical attitude fostered in, and essential to, scholarly culture can be a barrier to sharing knowledge with activists. Deborah, a junior scholar at a teaching intensive institution, did her dissertation on some organizations in her community and wanted to share her findings with them, but she worried about their reactions. The expectations of her scholarly work required a particular type of analysis and writing that was not necessarily useful for the organizations.

Deborah: So I really feel that the kinds of critiques that I had to engage of these groups in order to satisfy my committee made it harder for what I was writing to be acceptable and useful.

Interviewer: Oh, that's interesting. Tell me a little more about that.

Deborah: Well, it's like, I had to like, I liked some of my groups and I didn't like some of my other groups and I thought some of my groups were more problematic than others but you had to be balanced and you had to like interrogate this and that. I definitely felt like that - it was easy for my committee to expect a certain level of critique without realizing how hard it really was for these groups to be doing what they were doing.

Mary, a junior scholar at a teaching intensive institution who took her degree from a top 10 sociology program, reports being actively discouraged from pursuing public sociology. She got the implicit message that her research choices would have professional consequences, commenting that "We could have [worked with 
communities, done advocacy research], but we would have been run out of the department on a rail."

Challenging the hegemonic culture of the profession leaves those who are trying to do public sociology in a lonely place, lacking social and intellectual support. Most who do this work find themselves without a community of peers.

Deborah: My problem is I think my department would be fine with my activist standpoint, as long as I am focusing on my tenure case and I'm publishing in the right venues for tenure. But I don't have mentors who are public sociologists and I really miss that and I feel like I'm doing this on my own.

The relative isolation Deborah experiences is a common theme among public sociologists. Not only do they express frustration with the lack of colleagues to turn to for professional guidance, those who want to maintain the standards of their profession while also providing the community with a sociological perspective find themselves in a double bind. We can hear the internal debate so common for public sociologists in the words of Joan, a senior scholar at a research intensive institution:

... There is this wanting to avoid speaking off the top of my head when I really have an opinion on something. . . . but I don't really have something from my research, or that much more to say about it. And so I try to refer people to somebody else. But, like then I would like to insert a feminist perspective on this but really I don't want to in some way abuse, pretend an expertise, because I hate it when other people do that.

Trained into a discourse that makes their work difficult to use in service of the community, warned that doing community work will be devalued by their colleagues, lacking the mentorship of those who have honed the skills they never got in graduate school, and lacking experts to share the burden, many of the public sociologists we talked with are bumping against the discipline imposed by the profession's prevailing criteria for evaluating scholarly productivity and quality. As Diane Vaughan, a sociologist who has done work with the public writes, the "absence of rewards for public sociology in the discipline and/or the inability to connect to a supportive power base" makes sociologists less willing to engage in public or policy sociology (2005:414).

\section{Evaluation Practices}

Common criteria used to evaluate sociological scholarship create a stratification of sociologies that systematically pushes public sociology to the bottom. The kind of writing one does to communicate to the public is devalued by a scholarly culture in which accessibility is frequently the inverse of impressiveness, and publication outlets are ranked almost in inverse of the number of people who read them. Publication in the top-ranked journals is highly rewarded and those best for communicating to the public are formally devalued in scholarly culture. 
Karen, an associate professor who works at a research intensive institution reports:

We had to do this inventory for the university level-some indicators of progress or improvement or success - and we had to say what journals would we be really excited if somebody had a publication in. And, as you know, that's kind of hard because we have a diverse group and some people will never have something that would be published in $A S R$ [American Sociological Review]. And, they get pissed when that's the standard. They see it as a really biased journal. But there was agreement that Contexts should not be one of the journals because its goal is to educate the public and it's not considered sort of serious.

Laurie and Denise are both junior scholars at elite liberal arts colleges doing policy-relevant work that they hope will reach public audiences.

Laurie: I think that the fact that I've published in traditional academic venues is viewed very positively by, you know, like in terms of my promotion and tenure. I think that the fact that my work is not - that certain journals are not really accessible to the kind of stuff I do has impeded my professional development. I mean I think that if I had ASR pieces routinely, or even Social Forces, it would be very advantageous. And so the fact that I do work that doesn't fall into that rubric is problematic.

Denise: Well that is exactly the thing. I mean the chapter that ended up in that book [directed at policy makers] is pretty much devoid of any kind of theoretical literature. And so when I'm coming up for tenure next year (and that is something that I am proud of) [I want to] put it front and center on my $C V$. On the other hand, I do feel that I am under pressure to [produce] the peer-reviewed journal articles to demonstrate that, yes, I can talk the theoretical talk and meet the standards of the discipline.

The discipline values external funding, but public sociologists also find themselves on the down-side of a hierarchy among sources of this research support. The funders interested in work with community groups are not as prestigious as the National Science Foundation or the National Institutes of Health (NIH) that generally fund more basic research. Sally, a junior scholar at a research intensive institution, describes the situation at her school:

Yeah it's like - the assumption is that you're doing one thing or the other so if you're doing the state grant, then you're not getting the NIH grant so you're not getting the federal money.

The core document in the evaluation of scholarly worth is the curriculum vitae and the conventions for organizing and reading this text express the hierarchy of value in the profession. Particularly at research intensive institutions, the publication list appears near the top and conventional evaluators count the number of entries and weigh them by the prestige of the outlets. Teaching follows research, and service appears last and counts for the least (c.f., Sprague 1998).

Public sociologists often express difficulty juggling the sense of their contribution with the discipline's ranked and weighted categories. The artificial boundaries 
between teaching and research or research and service leave them at the mercy of their evaluators. Where does teaching a reporter about a research literature fall? How does one classify working with students in conducting research in the service of a community group? Conventional definitions equate public work with service - that is, not research and not teaching. Public work is then, by definition, relegated to the lowest status. Karen, for example, is a junior professor at a research intensive institution who did a heavy load of consulting work as the methodological expert for a state commission that was conducting policy-related research. She reported that her department "wouldn't even say, like, how many articles this would be worth. It's service."

Formal evaluation practices place significant emphasis not just on the prestige of the publication outlet but also on the quantity of publications. Public sociology simply takes more time, resulting in fewer publications. Behind every completed piece of research is a lot of invisible labor, but community-based or advocacy research includes extra layers of labor. It takes time to establish and maintain relationships of trust with community leaders and organizations. It takes time to teach undergraduates or community members to do research and to support them as they go through the daily pitfalls of the process. It takes time to cultivate relationships with reporters and help them hone a sociological imagination. All of this extra labor makes it hard for the engaged researcher to meet professional expectations for pace and quantity of products. As Deborah, a junior scholar at a teaching intensive institution notes, "There are people in some of our departments doing it [public sociology] and it has cost them severely."

Evaluation standards that disadvantage those doing public sociology put sociologists who are not from privileged backgrounds in a particularly difficult situation. Several scholars of color and/or working class sociologists describe their ties to their communities as less of a choice and more of a given. Their personal histories and networks tie them to communities struggling with significant social challenges they lack the resources to address. Janet is an associate professor at a teaching intensive institution:

[O]ne thing about that type of community work is that it puts a lot of pressure on you. And sometimes I can barely breathe. And I cannot-the problem is that this is not-I cannot use it for academia. So it's a kind of work commitment that I have, that I don't want to leave because it's part of me. And on the other hand, it, I guess it also adds - affects my academic time because, you know, those other things that I could use-because I'm doing them it takes away a little bit from the time for publishing or, you know, things like that.

For those who are connected to marginalized communities, the notion of objectivity and basic science can seem privileged and disconnected from the very real experiences of their struggling communities. Rather than conducting pure research that is only remotely connected to the pursuit of social betterment the "idea of putting scholarship to the service of their own communities' empowerment and well-being is more apt to sound like a sensible, if not an inevitable, way to practice 
their profession" (Hale 2008:3). Nora, a junior scholar of color at a research intensive institution describes it this way:

For some - particularly faculty of color-to give it [back], to recognize that our scholarship in some ways is very integrally linked to that public place and so that you can't like say, oh well, it's ok to do that as long as you get your research done. ...

There is an irony here. Departments go to great effort to recruit scholars who are historically underrepresented in the discipline presumably because this diversity enriches sociological discourse. Yet as a discipline we apply evaluation standards that exact a professional cost for producing knowledge that emerges from less privileged contexts. In spite of the cultural and evaluative barriers they report struggling with, many faculty in our sample report some form of engaged sociology, though the impact of institutional factors emerges once again in looking at who does what.

\section{Variations in Public Engagement}

Not all institutions have the same mission, and it is likely that local cultures develop in departments that deviate from the hegemonic culture of what some call "ASA sociology." We can see signs of this in the way the form of public engagement our informants report varies by institution type and career stage (Table 1). The group interviews began by asking each participant to describe the forms of public sociology they practice. The individual interviews did not ask this, however, so most of our frequency data on these activities comes from information volunteered during the course of the individual interviews. Of the 63 respondents, $17(27 \%)$ reported more than one kind of activity while $14(22 \%)$ of the individual interviewees reported no public sociology work at all. As a result, we must exercise care in interpreting the marginals of this table.

The largest proportion of our pooled informants (38\%) describes some connection to community groups, including advocacy organizations. Researchers' relationships with community organizations tend to be quite fluid and varied. Respondents conduct research with or for these organizations and also translate relevant sociological research so it is more accessible and useful to the groups with which they are involved.

A similar but smaller proportion (33\%) of respondents commented that they, at least occasionally, talk with reporters from newspapers, magazines, or local radio stations. These professors do interviews with media about their own research, the findings in their areas of research, or more frequently they provide informed insight to stories covered by local reporters. Just a few of these sociologists write specifically for mainstream media and/or appear quite frequently on the radio or have their own shows. The third most commonly reported public sociology activity, engaging a policy-oriented audience, is reported by approximately $20 \%$ of our informants.

Informants also said one way they attempt to do public sociology is to extend their campus teaching roles beyond the classroom. Some professors work with student groups presenting campus forums on policy questions. Others use some form of service learning to give students real-world exposure to people who live in 
circumstances contrasting with their own, to help them learn about social inequality, or they may incorporate community-based research for local organizations as a significant component of a class in research methodology.

Comparing across institution type and rank suggests that local culture and institutional demands impact the kinds of work informants do. Professors at top 25 departments, particularly junior faculty, report less public sociology work than informants at other types of institutions. The public work in which they are most likely to engage is working with the press - seven out of 15 having at least given an interview to a reporter. One full professor and one senior scholar with a non-tenure track post report working with community groups, and a third full professor has worked with government organizations and labor unions. Only one informant at a top 25 department reports doing public sociology through her teaching role, in this case via service learning.

Sociologists at less elite research intensive institutions report more varied public work and more of the junior faculty are engaged. While the ratio of junior faculty doing media work is the same, it is a little less common among senior faculty than in the top 25 group. This may reflect an institutional difference in opportunitynational media may seek interviews with scholars in big name institutions. The biggest contrast with the elite research institutions is in the case of work with the public more broadly. More than half of the faculty report some work with community groups and more than one in three senior faculty do policy related work or serve as expert witnesses based on research in their areas.

Faculty at teaching intensive institutions are comparable to those at research intensive institutions in their engagement with community groups, though senior scholars in this category seem a bit less likely to work with the media or do policy work. This could be a product of high teaching demands diminishing people's opportunity to keep up with a research literature, let alone their own research programs, while the length of time since graduate school training increases. On the other hand, here we find most of the people in our sample who report using their teaching role as a road to more engagement either through incorporating service learning in their classes or through working with student activists on their campuses.

In sum, institutional context seems to make a difference in how likely sociologists are to use their knowledge and skills for some public good. It may very well be that many sociologists in lower tier institutions across the country are doing what they can to bring the knowledge base of their discipline into some arena outside of the discipline. That question is outside of the scope of this paper and the possibilities of our data. If the pattern we see in Table 1 approximates the reality in the discipline though, at the very least what we are seeing is that scholars who have presumably the highest level of skill and the most time and resources to do research are focusing their efforts on the discipline. What's more, these are the people who are training the sociologists of the future. Of the 428 new sociology PhDs in 2000-2001, 362 earned their degrees at Research I institutions (ASA 2003).

\section{Self Presentation of Graduate Departments}

The picture our informants draw for us about the norms, values, and skills they learned in their graduate training is corroborated in the self presentation of 
programs who are training the next generation of sociologists. Using U.S. News and World Report's (2009) ranking of top doctoral programs in sociology we examined program descriptions, specialty areas, and degree requirements on the Web sites of the 53 departments ranking from 1 to 48 (the same rank can be assigned to more than one department) for evidence of formal programs or concentrations and other references to public sociology. Of these 53 departments, 6 (11\%) mention public sociology (or engaged sociology) on their Web sites.

The departments most prominently elaborating their support for "public sociology" on their homepages are the University of California-Berkeley (2009), the top-ranked sociology department, and the University of Illinois-Chicago (2009), ranked 41. Both describe the department's involvement and commitment to public sociology. The University of Illinois-Chicago highlights the work of two of the department's senior faculty. Berkeley does the same and adds videos of public sociology forums, interviews with faculty, and exemplary publications. Two other departments, the Department of Development Sociology at Cornell (2006), ranked 17, and University of Massachusetts-Amherst (2008), ranked 31, also mention public sociology. The University of Massachusetts-Amherst notes in the last sentence on the department "welcome" page that it "is at once committed to excellent education, basic research and to be a leader in the project of public sociology." The Department of Development Sociology at Cornell, the only department focused explicitly on developing knowledge and programs that will alleviate social problems, mentions its commitment to public sociology in its description of research in the department.

Finally, two other departments, 20th ranked University of Minnesota (2009) and North Carolina State University (2009), ranked 48, refer to themselves as "engaged departments" and describe being committed to a sociology that has an impact on our world. The University of Minnesota was featured as an exemplar of "the engaged department" in the American Sociological Association's, An Invitation to Public Sociology (2004).

That just 6 of the 53 top ranked sociology departments in the United States place enough value on public (or engaged) sociology to mention it on their Web sites and that none of these departments have any formal concentration in public sociology is telling about the status of such work in the discipline. Graduate students in these departments may be more likely to learn the necessary skills to practice public sociology, and faculty may be more likely to be rewarded for such work, but these programs are the exception, not the rule.

Earlier research suggests that if there is any institutional support for doing more engaged or applied forms of sociology, it is primarily happening in lower status institutions (Hand and Judkins 1999). There are joint departments that couple sociology with fields engaged in applying sociological ideas and methods, like Social Welfare or Criminal Justice, but these tend to be departments where the research mission has been captured by a more prestigious institution in the state and the department of sociology has taken a more applied focus (Hand and Judkins 1999). Similarly, there has been an increase in the number of sociology departments with applied programs, but most of the change has happened in Masters programs, not PhD programs (Hand and Judkins 1999). 
It could be that the six of the top 50 departments who are at least marketing themselves as training students are a harbinger of change that is in its early stages. Up until now, however, institutional barriers to doing public sociology have been generating negative consequences for individual sociologists and, we believe, for the discipline.

\section{The Costs of Maintaining the Barriers}

The institutional pressures against public sociology generate costs to the individuals who try to practice it, to the discipline's image with its various publics, and to the content of our knowledge base.

Many students come to sociology motivated by questions of social justice, but "graduate school seeks to expel that moral moment through a variety of disciplinary techniques - standardized courses, regimented careers, intensive examination, the lonely dissertation, the refereed publication, all captured by the all-powerful CV" (Burawoy 2004:104). Like graduate school, the tenure process selects for those who are willing to operate under the discipline's norms. Maureen is an assistant professor at a teaching intensive institution that requires her to have an active research agenda in order to get tenure.

Maureen: I would like to write more mainstream work. I would like to write a popular book. Because I just look at the level of discourse about gender and inequality and race and it sucks ... in the newspaper, on TV, whatever, whatever. So I really feel like there's still a big need for scholars like us to get the word out in some kind of mass way that's not insulting and not stupid but that is not academic crap either. So I think I would like a really general audience and then always simultaneously sort of having feminist sociologists reading me and critiquing me and supporting me.

Interviewer: So why don't you do more of the other at this point?

Maureen: I just don't feel like I can before tenure. I just think that kind of . . . I always hear people talking about, "well, she's fine, oh, she wrote a pop book." People think that's such a lame thing to do so I would like to be brave enough and have enough time to risk it before tenure, but I just don't realistically think I do .... And just I hate to say it, but I am still a little bit caught up in this wanting to be a good solid recognized sociologist. And I think I might hurt my case by writing a pop book.

One possible strategy for the people who want to do public sociology is to be "pure critical or professional sociologists before tenure and dance back and forth between critical (or professional) and public sociology after tenure, seeking to legitimate themselves with their colleagues as well as their publics" (Burawoy et al. 2004:119). Newcomers to the discipline have had less time under the influence of its professional discourses so are more likely to question conventional sociological approaches. By the time they make it through graduate school and the tenure process, how many will have retained the impulse to work against the grain of disciplinary values? 
The sociologists we talked to who have been trying to do public sociology within institutional constraints, pay a personal price. Our informants say they feel isolated and frustrated and one can hear the institutional barriers as they describe themselves as crossing over from one side of their work to another. Kate, a junior scholar at a teaching intensive institution put it this way:

I want to be a political . . my whole person as a sociologist, as a feminist, I didn't want to be compartmentalized but there is my scholarship and my teaching and here is my activism.

An excerpt from the group interview with junior scholars at teaching institutions reveals a similar experience:

Mary: I don't want to lead two different lives. I want to lead one life-

Deborah: Exactly.

Mary: - and I think I'm doing sociology in both lives so I don't understand why it has to be.

Many junior scholars, like Elaine, who is at a research intensive institution, literally hide the public side of their work:

Elaine: I volunteer and work for the battered women's shelter here in town, and I have to hide that.

Interviewer: Really?

Elaine: Yes. I have to hide that. And not necessarily because people think that's a bad thing to do, but because it's distracting from my scholarship. So [they think] I'm out doing all of these other things when I should be writing papers.

When asked, over half of the 50 feminist academics who were individually interviewed indicated they had thought about quitting. Like Eva, a full professor at a research university, they were careful to note that by quitting they meant quitting their job, not their work.

Now quitting is just quitting a job, it's not quitting my life commitment to so many issues. I don't quit my career and my ideals. I'd like to continue working on that. So what I mean by quitting - that's the way you phrased the question — quitting my job ... No, not my work. Not my LIFE work.

Some respond to the pressure by changing their career path. Approximately $20 \%$ of the academic feminists had left their initial tenure track positions, moving to departments that seemed more supportive of feminist work and/or to teaching focused institutions. They cited their desire for more time to devote to teaching and/ or community work and for that work to be valued. Emma, an associate professor at a research intensive university, contemplated the pull of an institution that would value her desire to have an impact on the world outside of the academy.

And I would like to work someplace where I could be somehow also supporting more community organizations. You know, helping them do research. Participatory action kinds of stuff. Helping them figure out what it is they need to do and help them find it out. Do more, more sociology in the service of society. Something like that. 
The Shedding of Disciplines and the Diminishment of Sociological Knowledge

We also believe that the discipline pays a price for failing to value public sociology. Recent research finds that administrators rank sociology low on measures of status and prestige (McNall 2008; Sargent and Hohm 2008). As a discipline, we face some distinctive challenges in this regard: our topic is vast and complex and that relative breadth of subject matter gives the impression of shallowness of content (Best 2001). Unlike the physical sciences, sociology's questions are not easily answered using highly abstract and experimental methods and when these methods are used they often result in interpretations so far removed from their subjects that their relevance is obscured ( $\mathrm{McNa}$ ll 2008). Because individuals must have a practical theory about their society in order to live within it, it is easy for them to think sociology has nothing new to tell them. Administrators and others admit that they can't understand all of economics but tend to think sociology is glorified common sense (Best 2001).

Sociology has made many contributions to intellectual life in the academy and to broader public discourse. Sociological principles, like the importance of the social in shaping behavior and phenomena, have been adopted across a wide range of disciplines (McNall 2008; Wimberly 1998). An amazing number of our key concepts have spread into public use: significant other, charisma, self-fulfilling prophecy, role model, and many, many more (Best 2001). Yet the discipline gets no credit (Best 2001; McNall 2008). Evidence of the value of the sociological perspective and its innovations comes from their application. However, rather than sociologists demonstrating the usefulness of their own frameworks and methods, that work is being done by scholars in the fields that the discipline has shed who then get the credit (Best 2001; Wimberly 1998).

Administrators also question sociologists' academic rigor (Downey et al. 2008; McNall 2008; Sargent and Hohm 2008). While they value the high enrollments our courses can generate, large numbers also contribute to assumptions that courses lack rigor and are simply easy ways for students to fulfill their graduation requirements (Downey et al. 2008). Undergraduates majoring in the physical sciences and psychology spend time in laboratories learning the skills of their disciplines and practicing their application. Those outside the academy understand such "apprenticeships" and recognize the relevance of this experience. On the other hand, while we tell our students sociology is useful, we do not show them what it is useful for and do not systematically train them to do such work (Wimberly 1998). Deans are critical of the lack of student involvement in research or other applications of disciplinary knowledge (Sargent and Hohm 2008).

The lack of broad public engagement contributes to a view of the discipline as "academic" in the pejorative sense that the work we do is not useful. It is striking that those few among the public sociologists who were recruited into doing media work via their institutional affiliation were not contacted through sociology but through women's studies, a discipline long known for its connection with and commitment to publics outside the academy. Virginia, a public sociologist who is an 
assistant professor at comprehensive institution, who does some work with the media, says we should:

somehow have the public know what sociology is - and if that's what we're trying to do with Contexts, you know, like psychology has Psychology Today. But you know what I get? The first thing I get from a radio interview is, you know, what is sociology? What can you bring to me?

We can compare the public's value for sociologists today to what McAdam (2007) reports about the post-WWII era when sociologists were engaged in research to address the problems of the time - often with public funding. Sociologists in some other parts of the world still get that respect as Joan, a full professor, at a top 25 institution, points out:

I think all of us would like to be speaking to the broader public somehow. But the question is what would be the mechanism. I guess because I do comparative work-I've seen colleagues of mine in Europe and Australia who have a much more direct link to policy makers. And they don't actually have to stop being academics. They're kind of given roles where they can do their research and it's taken up by policy bureaucrats. I don't think there's anything like that in the U.S. except for very applied social science types or economists.

\section{Conclusion}

Our findings are merely suggestive. Our respondents come disproportionately from research intensive universities and only $32 \%$ of sociology faculty were employed in Research I and II institutions in 2001 (ASA 2003). To accurately assess the local cultures and practices of the wide range of sociology departments and the values and desires of sociology faculty across the nation requires a larger, more systematic analysis. Still, our informants come from 54 different institutions and their experiences indicate that the hegemonic culture in our discipline makes it difficult for sociologists who have the most time and resources to do research to bring the skills and perspective of sociology to the service of the broader public.

We believe that sociology as a discipline has an ethical obligation to engage in public sociology. We have and will continue to develop knowledge that could help improve the lives of others and remedy serious social ills. How can we justify withholding that information? Many of us work at public institutions where our salaries and the resources we use to do our work are supported by taxpayers. Some receive additional funding from public agencies or private foundations whose nonprofit status means they are subsidized by taxpayers. Underlying this support is the assumption that what we do with our resources will benefit the community. Do we not have a responsibility to make sure there is some public return on the public's investment in us?

The impact on sociology is not just ethical, it is material. Instead of worrying about funding cuts and departments being disbanded because administrators, 
legislators, and taxpayers see our discipline as an unaffordable luxury, sociology could make itself indispensable to these publics. We have the right approach to understanding what makes societies work: social processes and social structures. We need to use the same approach to create structures and processes that will be the means for sociologists to develop and share useful knowledge.

\section{Breaking Down Barriers and Building Bridges}

If sociology wants a public role, the discipline must dismantle the barriers we present to those who want to do public sociology. We asked the public sociologists what would make it easier for them to do their work. Their responses provide a checklist for action.

The sociologists we talked with who are doing public sociology voiced appreciation for the work the American Sociological Association has already begun to do to transform the culture of the discipline to recognize and integrate public sociology. The ASA's (2008) Spivak grants and fellowships are important sources of both financial support and disciplinary legitimacy for them.

But there is more to do. The structure of the institution is evident as they describe what does not exist and what should. Many of the following requests are also on the agenda of those who are trying to make the discipline more of a home to applied sociology (Wimberly 1998). Interestingly, responding to theses requests would address the concerns of those who are worried about the impact of making sociology more public.

Without prompting, the public sociologists in each of the three group interviews asked the ASA to lead in the development of guidelines for evaluating work in the realm of public sociology. They would like workshops and sessions at annual meetings on the skills good public sociologists need, including how to improve community-based research methodology, how to increase effectiveness of service learning, and how to communicate to broader audiences about research. Awards to spotlight particular projects and offering funding to replicate successful efforts would provide more infrastructure to boost the scholarly quality and legitimacy of public sociology. Meeting these requests would also address the concerns of those who worry that public sociology might detract from scholarly rigor.

Graduate school training could better prepare students for working with the public. At the most basic level, our respondents would like to have learned how to write clearly and accessibly, particularly given their immersion in literatures that are jargon-laden and highly abstract. Those who do community-based research expressed a desire to have some training in how to cultivate relationships with community groups and how to work collaboratively with organizations while retaining strong standards of scholarship. Those who work with media said they wish they had had some guidance in how to exercise control over the message and how to screen outlets and reporters for trustworthiness. Dedicated graduate assistantships to support community-based research and teaching, and graduate certificates in policy-oriented research would allow students to hone their skills before they encounter the crush on time and performance that the tenure track presents. Institutional practices that train sociologists in effective public communi- 
cation would, over time, address concerns about how sociological ideas and findings can get over-simplified and distorted in public discourse.

Individual institutions can also make organizational adjustments that would make it easier to do high quality public sociology. Faculty who are engaged sociologists would like to see centers on their campuses that link research to policy needs. Ideally such centers would support networking among scholars with different forms of expertise and provide fellowships to fund policy-analysis and other forms of engaged scholarship. Course reductions would support the additional labor involved in teaching students and community members how to work together to generate useful sociological knowledge. Flexibility in course scheduling and teaching assignments would help compensate for the differences between academic timeframes and those of community actors. And, as many administrators already know, demonstrating the practical usefulness of scholarship created in their institutions increases public support for them.

Our discipline is organized to make public sociology more difficult than it has to be. As a result sociologists pay a cost as individuals and as a discipline. We can do things differently but it will require more than simply saying public sociology exists and has value. We will need to change the way we organize ourselves and evaluate one another.

\section{References}

American Sociological Association. (2003). How does your department compare? A peer analysis from the AY 2000-2001 survey of baccalaureate and graduate programs in sociology. Washington, DC: American Sociological Association. Retrieved July 29, 2009 (http://www.asanet.org/galleries/ Research/DeptRpt2001_Sect3.pdf).

American Sociological Association. (2004). An invitation to public sociology. Washington: American Sociological Association.

American Sociological Association. (2008). Community Action Research Initiative (CARI Grants): The Sydney S. Spivack Program in applied social research and social policy. Washington, DC: American Sociological Association. Retrieved July 25, 2009 (http://www.asanet.org/cs/root/leftnav/funding/ funding_overview).

Beck, U. (2005). How not to become a museum piece. The British Journal of Sociology, 56(3), 335-343.

Best, J. (2001). Giving it away: the ironies of sociology's place in academia. The American Sociologist, 21 (1), 107-113.

Blau, J., \& Smith, K. E. I. (eds). (2006). Public sociologies reader. Lanham: Rowman \& Littlefield.

Brady, D. (2004). Why public sociology may fail. Social Forces, 82(4), 1629-1638.

Braithwaite, J. (2005). For public social science. The British Journal of Sociology, 56(3), 345-353.

Burawoy, M. (2004). Public sociologies: contradictions, dilemmas, and possibilities. Social Forces, 82(4), $1603-1618$.

Burawoy, M. (2005a). 2004 American Sociological Association presidential address: for public sociology. The British Journal of Sociology, 56(2), 259-2594.

Burawoy, M. (2005b). Response: public sociology: populist fad or path to renewal? The British Journal of Sociology, 56(3), 417-432.

Burawoy, M. (2006). Introduction: A public sociology for human rights. In J. Blau, E. Keri \& I. Smith (Eds.), Public sociologies reader (pp. 1-18). Lanham: Rowman \& Littlefield.

Burawoy, M., Gamson, W., Ryan, C., Pfol, S., Vaughan, D., Derber, C., et al. (2004). Public sociologies: A symposium from Boston College. Social Problems, 51(1), 103-130.

Calhoun, C. (2005). The promise of public sociology. The British Journal of Sociology, 56(3), 355-363.

Cancian, F. (1992). Feminist science: methods that challenge inequality. Gender \& Society, 6(4), 623-642.

Cornell University. (2006). Department of development sociology. Retrieved on July 25, 2009 (http:// devsoc.cals.cornell.edu/). 
Deegan, M. (1988). Jane Addams and the men of the Chicago School, 1892-1918. New Brunswick: Transaction, Inc.

Downey, D. J., Wagner, W. E., III, Hohm, C. F., \& Dodson, C. J. (2008). The status of sociology in the academy: where we are, why we're there, and how to change it. The American Sociologist, 39(2-3), $193-214$.

Etzioni, A. (2005). Bookmarks for public sociologists. The British Journal of Sociology, 56(3), 373-378.

Hale, C. R. (2008). Introduction. In C. R. Hale (Ed.), Engaging contradictions: Theory, politics, and methods of activist scholarship (pp. 1-28). Berkeley: University of California Press.

Hand, C. M., \& Judkins, B. (1999). Disciplinary schisms: subspecialty 'drift' and the fragmentation of sociology. The American Sociologist, 30(1), 18-36.

Inglis, C. (2005). Comments on Michael Burawoy's ASA presidential address. The British Journal of Sociology, 56(3), 383-386.

Kalleberg, R. (2005). What is 'Public Sociology'? Why and how should it be made stronger? The British Journal of Sociology, 56(3), 387-393.

Lal, J. (2008). On the domestication of American public sociology: a postcolonial feminist perspective. Critical Sociology, 34(2), 169-191.

Lipsitz, G. (2008). Breaking the chains and steering the ship: How activism can help change teaching and scholarship. In C. R. Hale (Ed.), Engaging contradictions: Theory, politics, and methods of activist scholarship (pp. 88-111). Berkeley: University of California Press.

McAdam, D. (2007). From relevance to irrelevance: The curious impact of the sixties on public sociology. In C. Calhoun (Ed.), Sociology in America: A history (pp. 411-426). Chicago: University of Chicago Press. An ASA Centennial Publication.

McNall, S. G. (2008). Save the world on your own time: or, what's the matter with sociology? The American Sociologist, 39(2-3), 142-154.

Mendez, J. B. (2008). Globalizing scholar activism: Opportunities and dilemmas through a feminist lens. In C. R. Hale (Ed.), Engaging contradictions: Theory, politics, and methods of activist scholarship (pp. 136-163). Berkeley: University of California Press.

Miles, M. B., \& Huberman, A. M. (1984). Qualitative data analysis: A sourcebook of new methods. Thousand Oaks: Sage.

Nabudere, D. W. (2008). Research, activism, and knowledge production. In C. R. Hale (Ed.), Engaging contradictions: Theory, politics, and methods of activist scholarship (pp. 62-87). Berkeley: University of California Press.

Nielsen, F. (2004). The vacant 'We': remarks on public sociology. Social Forces, 82(4), 1619-1627.

North Carolina State University. (2009). Department of Sociology. Retrieved on July 25, 2009 (http:// sociology.chass.ncsu.edu/).

Sargent, P., \& Hohm, C. F. (2008). Sociology in the academy: a study in contradictions? The American Sociologist, 39(2-3), 181-192.

Sassen, S. (2005). Digging in the penumbra of master categories. The British Journal of Sociology, 56(3), $401-403$.

Scott, J. (2005). Who will speak, and who will listen? Comments on Burawoy and public sociology. The British Journal of Sociology, 56(3), 405-409.

Singleton, R. A., Jr., Straits, B. C., \& Straits, M. M. (1993). Approaches to social research (2nd ed.). New York: Oxford.

Smith, D. E. (2005). Institutional ethnography: A sociology for people. Walnut Creek: AltaMira/Rowman \& Littlefield.

Sprague, J. (1998). (Re)Making sociology: breaking the bonds of our discipline. Contemporary Sociology, $27(1), 24-28$.

Sprague, J. (2005). Feminist methodologies for critical researchers: bridging differences. Walnut Creek: AltaMira/Rowman \& Littlefield.

Stacey, J. (2004). Marital Suitors Court Social Science Spin-sters: The unwittingly conservative effects of public sociology. Social Problems, 51(10), 131-145.

Strauss, A., \& Corbin, J. (1990). Basics of qualitative research: grounded theory procedures and techniques. Thousand Oaks: Sage.

Swidler, A., \& Arditi, J. (1994). The new sociology of knowledge. Annual Review of Sociology, 20, 305-329.

Tittle, C. R. (2004). The arrogance of public sociology. Social Forces, 82(4), 1639-1643.

University of California-Berkeley. (2009). Department of Sociology. Retrieved on July 25, 2009 (http:// sociology.berkeley.edu/).

University of Illinois-Chicago. (2009). Department of Sociology. Retrieved on July 25, 2009 http://www2. las.uic.edu/depts/soc/. 
University of Massachusetts-Amherst. (2008). Department of Sociology. Retrieved on July 25, 2009 (http://www.umass.edu/sociol/).

University of Minnesota. (2009). Department of sociology. Retrieved on July 25, 2009 (http://www.soc. umn.edu/).

U.S. News and World Report. (2009). Rankings: Sociology. Retrieved July 25, 2009 (http://grad-schools. usnews.rankingsandreviews.com/best-graduate-schools/top-sociology-schools/rankings).

Vaughan, D. (2005). On the relevance of ethnography for the production of public sociology and policy. The British Journal of Sociology, 56(3), 411-416.

Weiss, R. S. (1994). Learning from strangers: The art and method of qualitative interview studies. New York: Free.

Wimberley, R. C. (1998). Applied sociology? Even musicians give concerts. The American Sociologist, 29 (4), 5-19. 